\title{
Rapid change in Deccan volcanism triggered by delamination prior to Chicxulub impact
}

\author{
Patrick A. Hoyer ${ }^{1}$, MARCel Regelous ${ }^{1}$, Karsten \\ M. HAASE ${ }^{1}$ AND FRÉDÉRIC FlUTEAU ${ }^{2}$ \\ ${ }^{1}$ GeoZentrum Nordbayern, Universität Erlangen-Nürnberg, \\ Schlossgarten 5, D-91054 Erlangen, Germany \\ (*correspondence: patrick.hoyer@fau.de) \\ ${ }^{2}$ Institut de Physique du Globe de Paris, 1 Rue Jussieu, 75238 \\ Paris, France
}

The Deccan Traps of NW-India overlap in age with the devastating biotic crisis at the Cretaceous-Paleogene boundary ( $\sim 66 \mathrm{Ma}$; KPB), during which about $75 \%$ of species became extinct. Approximately $70 \%$ by volume of the total Deccan CFB may have been erupted within about 500 thousand years, starting at or shortly before the KPB. The apparent coincidence of the initiation of the most voluminous Deccan eruptions with the KPB has led to the suggestion that the seismic energy of the Chicxulub impact triggered a fundamental shift in the Deccan magmatic plumbing system $[1,2]$. A rapid change in the mantle melting processes should be recorded in the geochemical stratigraphy of Deccan lavas. Here we present major element and ICP-MS trace element data for 171 samples covering almost the complete Deccan stratigraphy, from the Jawhar to Mahabaleshwar formations $[3,4]$. We confirm a change to mantle-dominated compositions starting at the base of the Poladpur Formation. We also find that trace element compositions of Deccan lavas change significantly within the Khandala formation. $\mathrm{Ce} / \mathrm{Pb}$ and $\mathrm{Nb} / \mathrm{Th}$ ratios decrease, indicating a change to higher degrees of crustal contamination, and $\mathrm{Sm} / \mathrm{Yb}$ but not $\mathrm{La} / \mathrm{Sm}$ decreases into the overlying Bushe Formation. Based on rare earth element modelling, we show that this change was likely caused by a rapid transition to shallow mantle melting, due to a decrease in lithospheric thickness from at least $135 \mathrm{~km}$ to 90 $\mathrm{km}$, possibly triggered by plume-induced delamination, which occurred $100-200$ kyr before the Chicxulub impact. Our model can also explain the increase in magma production rates and the less contaminated compositions of the younger Deccan lava formations.

[1] Richards et al., GSA Bulletin 127 (2015) 1507-1520

[2] Renne et al, Science 350 (2015) 76-78

[3] Chenet et al., JGR 113 (2008)

[4] Chenet et al., JGR 114 (2009) 